\title{
Constructing Knowledge of the Urban Site
}

\author{
ANDREA KAHN \\ Columbia University \\ USA
}

This paper considers a fundamental but underexamined aspect of the urban design process: site analysis - or the production of site knowledge. While integral to design thinking, site analysis has historically sustained a notable lack of critical or theoretical attention in either architectural or urban design discourse. Because of this oversight, the assumptions and values underlying analysis methods are rarely, if ever, submitted to review. To reveal the formative role of site analysis in urban design thinking, this paper begins with a brief discussion of analysis, generally. It is followed by an equally abridged look at the conceptual biases of standard site descriptions and how these can effect urban design. Finally, I conclude with a few suggestions for an alternative approach to urban site study, which moves beyond the myth of analytic objectivity to posit analysis as the initiation of design.

To examine how site knowledge is produced demands attention to formative relationships between how different site measures are applied, the kind of descriptions these engender, and the degree of authority such descriptions assume when imagining possible site futures. At issue here are fundamental aspects of the urban design process (perhaps one reason site analysis has been so underthought - since it invokes very basic issues):

1. Site representation and its influence on concepts of what a site is and might become;

2. Site study methods informed by these modes of site representation; and

3. Programming strategies grounded in site-study practices. Many questions constellate along theseintersecting trajectories: Among them, how do attitudes toward site analysis, and assumptions about representation together lead to a particular kind of site knowledge? How does this knowledge determine what we do, and do not recognize as a site? How would thinking about site differently alter its description or conversely, how would alternative descriptions modify its conception? Today I will take up a small part of this inquiry, to consider relations between how we frame - or sight the urban site and the tools used to describe what we find.

The urban site will always overwhelm as an object of critical and theoretical reflection. With a blatant disregard for designs orderly representations, the images and identities of the city remain elusive. This is because the urban site is not a stable place, but instead a transitory and multivalent space - an aggregation of ever shifting scales, programs, and actors, all set within a temporal framework that holds both prior traces and future modifications. What characterizes an urban situation is not a singular form or name, but actions, and with these a resistance to simple inventory. Nevertheless, architects, planners and developers still prefer to apprehend urban sites as finite and determinate. In the face of ever changing urban conditions, the myth of a knowable, and controllable urban site continues to hold sway. Its tenacity is linked first, to the assumption that the goal of design is the production of order, and second, to the expectation that the role of analysis is to prepare clear and comprehensive site images, to ease the imposition of designs controls.

Because analysis techniques and conventions of analytic representation stress definitive site knowledge, they contribute to the incommensurability between ideal, ordered urban visions and more disorderly urban realities. This problem is due, in part, to the (always unattainable) desire for objectivity that characterizes analysis generally, and contributes, more specifically, to an analysis myth about site study associated with design. This myth is a fiction sustained with regard to the conceptual site of the analysis process, and is construed by three interrelated assumptions: First, that site analysis is inconsequential to site definition. In other words, site limits are typically set before the analysis process begins, and site study in not considered to have impact on the determination of site boundaries. Second, that the site descriptions associated with analysis are neutral records of empirical site "data" (recorded using graphic conventions that will not be adopted in subsequent phases of design). And, third, that analysis is pre-design (evidence of this can be found both in the use of specific graphic conventions, distinct from those used in "design" phase and in the sequencing of analysis in the design process as a whole).

In a discussion of objectivity in the social sciences, Max Weber notes that the number and type of causes influencing any given event are always infinite and that nothing in the things themselves sets some causes apart as alone meriting attention. Paraphrasing Weber: the number and type of causes constituting any urban site are always infinite, and 
order is brought to site on the condition that only a part of it is interesting and significant to us, because only this part is related to the disciplinary values with which we approach it.' As Weber makes clear, site analysis (because it ascribes value to particular site attributes) is always an interpretive practice. So, although the analysis myth holds that site study is value free and preparatory to design, and that site knowledge is simply uncovered by analysis methods, in fact, this knowledge is always construed through, and is always a manifestation of, those cultural (disciplinary, and design) values prescribed by the analysis process itself.

The analysis myth can endure because of the presumed objectivity of site docments, which leads to their misinterpretation as empirical observations. In actuality, however, these representations are ideologically loaded and value-laden constructions. They plot the site and set it up for the next level of design intervention. Depending on the choice of analytic frames, and the values these frames express, the described site will always assume a distinct configuration directly related to specific design strategies. On one hand, the logics and values structuring initial site observations will already be prescribed by expectations about the scope and character of a sites later development; and on the other hand, the analysis process will always initiate a way of thinking about site that resonates through all phases of design. The outcome of analysis is effectively a programming of site - its methods will always be part of a concerted effort to record the site in ways that most easily match future design interventions. Precisely because of this inescapable relation of analysis to design, site study methods and their representational devices ought to be more critically approached.

\section{STANDARD SITE STUDIES}

Although considered a pre-design activity, then, site analysis is inevitably bound up with - prefigured by - design intentions. It is the initial moment of design. Consider standard site analysis: To present a clear and comprehensive rendering of a site, conventional analysis documents priviledge the plan, the omnicient point-of-view. This gaze that overlooks - in this sense, superintends - imposes a maximal degree of spatial (and temporal) order on site. Hovering above the surface (unlike a section, for example, that cuts through resistant materials) the plan diminishes the legibility of crucial conflicts at ground level. Standard analysis documents draw out categorical distinctions (use, building type, block morphology, infrastructure, formal patterns, class, etc.). The problem with such distillation is that the disparate aspects and scales structuring a site cannot be so simply disentangled. In plans that plot like with like, the urban site is split along non-existant seams. Through acts of inventory, visible and invisible overlaps (or resistances), or copresent (and most likely discordant) site conditions are neglected. In standard descriptions what remains unaccounted for is anything that cannot be assigned a "proper" place fluid reciprocities, interlocking events and tensive scalar relations that constellate vital urban situations and evade simple classification.

Take, for example, the figure/ground drawing - a wellknown drawing associated with urban site analysis. In the 1700 s Nolli's plan of Rome marked a revolutionary moment in conceiving the spatial and experiential structure of the city. However, when applied today as an analytic tool to sites built under entirely different economic, social, and political circumstances, the Nolli convention poses serious difficulties. While a discussion of the uses and abuses of the figure-ground would make a lecture in itself, suffice it to say that often the tools we use to construe site are derived from a previously sanctioned lexicon of precedents (for example, formal orders, morphological patterns, or traditional philosophical and scientific conceptions of space) that reassert notions of site and ideas about its probable configurations that may not be applicable today. Viewing the urban site through the lens of the Nolli-based figure ground, we seek out certain, known conditions - "consistent street walls," "clear figurative spaces," "unbroken urban fabric" because this mode of representation priviledges their description. Conversely, when what is found on site resists simple classification according to externally derived criteria, it tends to be disregarded. The oppositional, black and white context of the figure ground, can never account for the grey fields characterizing the contemporary city among these privatized public spaces that are neither fully open nor totally closed to the street system; highway overpasses and underways, at one moment reading as figure, at another, holding the ground; or non-figural spaces that figure prominently in the perceptin of an site, like the sheared wall of city street, not a facade but an edge nonetheless. Consequentially, these and similarly "unclear" situations go unrecorded.

Approaching any specific site, we want it to either confirm, or conform to, expectations we hold regarding notions of site, generally. Those site aspects that drop from view will always be somehow in conflict with these traditional site definitions, held in place by conventional modes of site description. All sites are an aggregation of elements, systems and events, yet few necessarily obey the same rules or submit to identical measures. In the interest of presenting a coherent site image, however, the superimposition of an applied order represses site aspects that fail to conform to the rule. What results is an underarticulation - an erasure, a smoothing over, or a flattening out of the contestatory. In response to design difficulties posed by the many conflicting spaces that coexist on any urban site, plan drawings (in particular) tend to circumscribe them all by a single boundary condition. In this delineatory action the site, which is always an expansive condition, is suddenly conflated with a "building lot." This act of containment, in turn, dissociates the urban site from its surroundings and denies its multiscalar realities. What results is an objectification of site. This objectified site image takes various conflicting views and replaces them with a single dominant one - it effectively submits the urban site to reductive controls. Forfeited here is 
what Carol Burns calls "the surplus of site."

This loss of site knowledge - or perhaps more accurately, this repression of site knowledge - has profound design implications. When it oversimplifies a sites lived complexity, analysis effectively initiates an attitude toward programming as well as architectural and urban scale design that priviledges controllable conditions and devalues open-ended situations. The resultant urban projects will thrive on clear delineations-preferred uses, proper forms and correct behaviors, they will draw out oppositions to create specialized tracts dedicated to particular classes or kinds of activity. My point is the following: Urban design based on site analysis as inventory leads to programming strategies that lift out and separate differences. It results in an urbanism that makes manifest the effects of analytic categorization - discrete and distilled object buildings that are disconnected from the natural flows of their surroundings, single-scaled schemes that overlook the multiple orders of site to impose their own singular rule. Further, because of the impact of the "analysis myth," these essentially anti-urban projects are legitimated on the basis of site descriptions presumed objective, and for that reason, beyond question.

\section{ALTERNATIVES}

As an alternative to standard site analysis, site construction is a process of ferreting out urban values embedded in the urban site itself. Site construction neither looks for not represents a lack. Nor does it impose controls based on external measures. Instead, by discerning diversely scaled, site-specific characters from physical and non-physical site attributes, site construction is the critical hinge between how the city is seen and what it might become. As a site study process, Site construction has both conceptual and material force. Its role is similar to that of history as described by Alan Colquhoun. To paraphrase, Site Construction provides the critical ideas necessary to project urban programming strategies as well as the urban material out of which these programs are formed.

By providing a way to think about and represent the urban site in a non-reductive and non-objectified manner, site constructions pose a challenge to those powers held in place by more divisive analysis methods - those that break down the urban as a way of preparing it for colonization by design announced in a rhetoric of control. Site construction modifies standard analysis and its modes of representation to confront an impermanent urban ground. Regional, metropolitan, local and global; permanent andmutable; close and distant: each vantage point brings different aspects of the urban site to light and each way of organizing site information (politically, economically, formally, historically, spatially, etc.) results in a distinct site configuration. Individually, these expose a predilection toward some combination of the city's myriad characters; drawn together, the many approaches begin to approximate the multivalence built into the urban landscape. As such, instead of providing a singular image of the urban site, the purpose of site constructions is to account for the urban site as a continually, and continuously shifting territory.

At issue here is the determination of a sites limits, which directly informs how it is perceived. Any site is experientially expansive; despite the delineation of a site boundary, the area contained within it will always remain perceptually part of a larger surroundings. Nevertheless, conventional analysis methods conceptualize site as a discrete area of land bounded by abstract delineations (which tend to ignore physical configurations such as geography or topography, as well as marks of everyday inhabitation). To revise the conception of urban sites thus requires a fundamental repositionning with respect to their definition - thinking them not as static figures but as mobile ground. To effect this change is as simple as acknowledging that a sites boundaries always shift in relation to the position - the physical location and ideological stance - of their beholder. Most importantly, the result of this reorientation is the recovery of a lost urban ground. We retreive and expand the urban territory upon which we build by admiting that every site is a mutable constellation - that it operates at many scales and accommodates potentially discontinuous, or even conflicting spaces in the same place.

Construed as a critique, site construction inverts standard site analysis methods. It admits the inadmissible, dropping any pretense of objectivity to openly adopt necessarily incomplete and biased points-of-view. It is based on the premise that any site study involves choosing how to describe and what to frame, and that these choices always reflect design predilections. In the Site Construction process, frames of reference and criteria for judgment are announced as interpretive, derived from the conjunction of a viewers position with particular (visible and invisible) site conditions. The choice of these frames is explicitly posited as the initiation of design: site study as the construction of a designed understanding of site. Accepting the impossibility of objective site knowledge, Site Construction no longer denies the hidden design agendas of analysis. Here, the crucial but rarely acknowledged connection between site study and site design is taken to account. As a revised site study process that breaks from the myth of analytic objectivity, site construction has profound implications for how the city develops, because it directly informs the urban programming practices that structure design actions. It works against objectified, distilled and parcellized site knowledge-and its allied forms of site development - by challenging the tacit values embedded in conventional modes of site representation. Announced as partial, site cons ruction argues for the urban site as diversely constituted - and for the city as a project at once impermanent and forever incomplete.

\section{NOTES}

1 For a discussion of Weber's work on analytic value judgements, see J. Nicholas Entrikin, The Betweenness of Place, Towards a Geographyof Modernity (Baltimore: Johns Hopkins University Press, 1991) $84-102$

${ }^{2}$ Carol Burns, "On Site: Architectural Preoccupations," in Andrea Kahn, ed., Drawing/Building/Text (New York: Princeton Arhitectural Press, 1991) 165 